\title{
EVALUASI KINERJA MAHASISWA MAGANG DI HOTEL BINTANG 5 (*****)
}

\author{
Regina Dewi Hanifah \\ Akademi Pariwisata Bunda Mulia \\ email: rhanifah@bundamulia.ac.id
}

\begin{abstract}
Abstrak
Latar belakang penelitian ini berangkat dariminimnya tenaga kerja yang memiliki kualifikasi yang dibutuhkan oleh hotel saat ini. Para lulusan yang dicetak oleh institusi masih belum dapat memenuhi kebutuhan hotel, sehingga akhirnya masing-masing institusi berlomba untuk membuat kurikulum yang mengakomodir kebutuhan pengguna di industri perhotelan yang penuh dengan kemampuan praktikal. Salah satunya menggunakan program on the job training di hotel, khususnya hotel bintang 5 dengan standar terbaik menjadi jembatan bagi para mahasiswa untuk dapat membantu menerapkan ilmu pengetahuan yang diperoleh di institusi ke dalam dunia kerja dan dapat membantu dalam berpola pikir dan bertindak dalam memecahkan masalah yang ditemui pada lingkungan kerja.Tujuan dari penelitian ini untuk mengukur kinerja para mahasiswa saat magang, dimana penilaian tersebut menjadi tolak ukur keberhasilan dari rancangan kurikulum dan penyampaian pembelajaran di sebuah institusi pendidikan. Metode yang digunakan menggunakan sampel mahasiswa Akademi XYZ yang melakukan OJT di Hotel Bintang 5 di seluruh Indonesia sebanyak 36 orang mahasiswa yang terdiri dari semester 3 dan 5. Pengumpulan data dilakukan dengan penyebaran kuesioner berbentuk formulir penilaian mahasiswa dengan skala yang mengikuti penilaian akademis, serta interview dengan Training Manager Hotel dan mahasiswa. Hasil yang ditemukan dengan menggunakan 5 kategori penilaian berdasarkan teori kinerja dari Bangun (2012), nilai kinerja mahasiswa Akademi XYZ berada dalam kategori sangat baik dengan tolak ukur penilaian akademis yang berlaku di Akademi XYZ. Adapun nilai tertinggi adalah kemampuan kerjasama sebesar 8,86 dan terendah adalah kualitas pekerjaan sebesar 8,43 . Hal ini dapat berimplikasi kepada kesiapan mahasiswa di dunia kerja yang tidak dapat berkembang, sehingga sangat dibutuhkan penambahan materi yang berkenaan dengan kualitas kerja di dalam kegiatan pengajaran bagi mahasiswa.
\end{abstract}

Kata kunci: Kinerja, Mahasiswa, On The Job Training, Hotel

\begin{abstract}
Background of this research departs from the lack of workers who have the qualifications needed by hotels. The alumni who were graduated by the institution still could not meet the needs of the hotel, finally each institution competed to create a curriculum that accommodated the needs of users in the hospitality industry which was full of practical abilities. One of them is using on the job training program in hotels, especially 5-star hotels with the best standards to be a bridge for students to be able to help apply the knowledge gained at the institution to the world of work and can help in thinking and acting in solving problems encountered. in the work environment. The purpose of this study is to measure the performance of students during an internship, where the assessment is a measure of the success of curriculum design and delivery of learning in an educational institution. The method used was a sample of XYZ Academy students who conducted OJT at 5-Star Hotels throughout Indonesia totaling 36 students consisting of semesters 3 and 5. Data collection was carried out by distributing questionnaires in the form of student assessment forms on a scale that followed academic assessments, as well as interviews with Hotel Training Manager and students. The results found by using 5 assessment categories based on the performance theory from Bangun (2012), the performance scores of XYZ Academy students are in very good category with the academic assessment benchmarks applicable at XYZ Academy. The highest value is the ability of cooperation by 8.86 and the lowest is the quality of work by 8.43. This can have implications for the readiness of
\end{abstract}


students in the world of work that cannot develop, it is very necessary to add material related to the quality of work in teaching activities for students.

Keywords: Performance, Students, On The Job Training, Hotel

\section{INTRODUCTION}

Penginapan adalah salah satu akomodasi yang dibutuhkan oleh wisatawan dalam melakukan kegiatan, tetapi tidak hanya layanan penginapan yang dibutuhkan wisatawan, tetapi layanan pendukung lainnya yang akan mempengaruhi kebutuhan para wisatawan. Menurut Sulastiyono (2011), hotel adalah perusahaan yang dijalankan oleh pemiliknya dengan menyediakan layanan makanan dan minuman dan fasilitas ruang tidur untuk orang yang bepergian dan mampu membayar jumlah yang wajar sesuai dengan yang diterima penerima tanpa perjanjian khusus.

Industri perhotelan di Indonesia terus semakin berkembang seiring dengan perkembangan dunia usaha, hal ini ditandai dengan bertambahnya jumlah hotel yang ada pada saat ini. Dengan perkembangan tersebut persaingan antar hotel akan semakin meningkat. Oleh sebab itu, industri perhotelan harus didukung oleh berbagai aspek agar dapat bersaing dengan hotel lain. Bukan hanya pelayanan yang baik, akan tetapi diperlukan juga adanya kebutuhan dan kenyamanan yang berhubungan erat dengan perilaku penghuni hotel.

Tentunya untuk memberikan pelayanan yang baik dibutuhkan juga sumberdaya dengan kinerja dengan performa yang baik. Hal ini untuk mendukung kualitas layanan yang akan diberikan kepada para tamunya. Dimana para tamu akan merasakan pelayanan yang sempurna bila para karyawan di dalam hotel dapat bekerja sesuai standarnya dan bahkan diatas standarnya.

Menurut Bangun (2012), Kinerja adalah hasil kerja yang dicapai oleh seseorang berdasarkan persyaratan pekerjaan (persyaratan pekerjaan). Pekerjaan memiliki persyaratan tertentu yang harus dilakukan dalam mencapai tujuan yang disebut standar pekerjaan. Standar Performance adalah tingkat yang diharapkan dari pekerjaan tertentu yang harus diselesaikan dan merupakan pembanding (benchmarks) dari tujuan atau target yang ingin dicapai. Untuk dapat memasuki industri yang sangat kompetitif, membutuhkan tenaga kerja terampil agar tetap menjadi perusahaan yang sukses dalam permainan kompetitif industri.

Salah satu hambatan yang terjadi di tempat kerja adalah kurangnya pelatihan dan pengembangan.Dalam memenuhi jumlah sumber daya yang selalu meningkat maka insitusi pendidikan tinggi dan gelar sarjana serta diploma perhotelan yang ditawarkanpun turut meningkat. Meskipun dinyatakan tumbuh semakin banyak, penelitian menunjukkan bahwa industri masih mempertimbangkan ada kekurangan tenaga kerja terampil yang memenuhi tuntutan industri (Joslam, et al., 2009; Richardson, 2012; Wan, Vong, dan Kong, 2010)

Program Studi Diploma III Perhotelan Akademi XYZ dikelola berpedoman pada visi, misi, sasaran dan tujuan sesuai perkembangan keadaan. Sesuai dengan Visi yang dimiliki maka sistem pembelajaran disesuaikan dengan keadaan industri yang ada saat ini dan terus mengembangkan inovasi lainnya agar lulusan dari Akademi XYZ dapat bersaing saat lulus nantinya. Untuk itu pengembangan kurikulum Akademi XYZ dilakukan dengan total beban studi 110 sks yang dapat ditempuh selama 6 (enam) semester. Proses bimbingan karir bagi para mahasiswa sudah dimulai sejak On The 
Job Training sepenuhnya dikelola oleh Program Studi, dimana Program Studi ini membantu mahasiswa dalam hal penempatan di industri perhotelan baik yang ada di Jakarta, Bandung, Yogya, Bali, maupun di Malaysia. Kegiatan OJT ini dilakukan selama 6 bulan (1 semester) di semester 3 dan juga semester 5. Dimana Akademi XYZ sendiri memiliki standar pemilihan hotel di bintang 4 dan bintang 5 baik di dalam maupun luar negeri untuk penempatan mahasiswanya. Hal ini untuk memberikan kebutuhan pengetahuan dan keterampilan secara praktis dengan standar layanan hotel tertinggi, dimana mahasiswa belajar layanan seperti apakah yang maksimal bisa diberikan kepada para pelanggan. Sehingga lulusan dari Akademi XYZ saat lulus telah mendapat 2 kali pengalaman bekerja di industri perhotelan dengan standar minimum hotel bintang 4 .

Tujuan dari penelitian ini adalah untuk mengevaluasi kinerja mahasiswa saat melakukan program magang di hotel bintang 5 dimana pemilahan ini dilakukan untuk dapat memperlihatkan kualitas mahasiswa di kategori hotel dengan bintang tertinggi. Dari penilaian tersebut dapat terlihat kategori mana yang perlu ditingkatkan bagi mahasiswa untuk kedepannya menjadi masukan bagi institusi dalam mendidik dan juga membuat teknik pengajaran yang memenuhi kebutuhan industri saat ini.Sehingga nantinya para lulusan dapat memenuhi kebutuhan industri perhotelan sesuai kualifikasi masing-masing pekerjaan di setiap departemen dalam hotel.

Oleh karena itu penulis mencoba untuk dapat mengevaluasi kinerja dari mahasiswa yang diberikan oleh Hotel bintang 5 yang dilaksanakan oleh mahasiswa Akademi XYZ dalam periode magang di bulan Juli-Desember 2018. Dimana dari penilaian tersebut dapat terlihat faktor dari kinerja manakah yang memiliki nilai terbesar atau terendah yang dimiliki dari mahasiswa Akademi XYZ., untuk nantinya dilakukan tindak lanjut dalam persiapan pemberian materi dalam perkuliahan.

\section{Kajian Literasi}

On the Job Training merupakan suatu proses yang terorganisasi untuk meningkatkan keterampilan, pengetahuan, kebiasaan kerja dan sikap, dengan cara calon pekerja ditempatkan dalam kondisi pekerjaan yang sebenarnya, dibawah bimbingan dan pengawasan dari pegawai yang telah berpengalaman. Menurut Swasto (2011) on the job training adalah suatu kegiatan pelatihan yang dilakukan ditempat kerja, dimana seorang mempelajari pekerjaan dengan melaksanakannya secara aktual dalam pekerjaan. Pengalaman on the job training sangat berperan dalam membantu mahasiswa untuk menerapkan ilmu pengetahuan yang diperoleh di kampus ke dalam dunia kerja yang sebenarnya dan juga dapat membantu dalam berpola pikir dan bertindak dalam memecahkan masalah yang ditemui pada lingkungan kerja. Pool dan Sewell (2007) mengutarakan bahwa pengalaman kerja dalam bentuk paruh waktu sekalipun bisa membantu meningkatkan kesiapan kerja.

Untuk memudahkan penilaian kinerja karyawan, standar pekerjaan harus dapat diukur dan dipahami secara jelas. Menurut Bangun (2012) Suatu pekerjaan dapat diukur melalui jumlah, kualitas, ketepatan waktu mengerjakannya, kehadiran, kemampuan bekerja sama yang dituntut suatu pekerjaan tertentu.

\section{Jumlah pekerjaan}

Dimensi ini menunjukan jumlah pekerjaan yang dihasilkan individu atau kelompok sebagai persyaratan yang menjadi standar pekerjaan. Setiap pekerjaan memiliki persyaratan yang berbeda sehingga menuntut karyawan harus memenuhi persyaratan tersebut baik pengetahuan, keterampilan, maupun kemampuan yang sesuai. Berdasarkan persyaratan pekerjaan tersebut dapat 
diketahui jumlah karyawan yang dibutuhkan untuk dapat mengerjakannya, atau setiap karyawan dapat mengerjakan berapa unit pekerjaan.

\section{Kualitas pekerjaan}

Setiap karyawan dalam perusahaan harus memenuhi persyaratan tertentu untuk dapat menghasilkan pekerjaan sesuai kualitas yang dituntut suatu pekerjaan tertentu. Setiap pekerjaan mempunyai standar kualitas tertentu yang harus disesuaikan oleh karyawan untuk dapat mengerjakannya sesuai ketentuan. Karyawan yang memiliki kinerja baik bila dapat menghasilkan pekerjaan sesuai persyaratan kualitas yang dituntut pekerjaan tersebut.

\section{Ketepatan waktu}

Setiap pekerjaan memiliki karakteristik yang berbeda, untuk jenis pekerjaan tertentu harus diselesaikan tepat waktu, karena memiliki ketergantungan atas pekerjaan lainnya. Jadi, bila pekerjaan pada suatu bagian tertentu tidak selesai tepat waktu akan menghambat pekerjaan pada bagian lain, sehingga memengaruhi jumlah dan kualitas hasil pekerjaan.

\section{Kehadiran}

Suatu jenis pekerjaan tertentu menuntut kehadiran karyawan dalam mengerjakannya sesuai waktu yang ditentukan. Ada tipe pekerjaan yang menuntut kehadiran karyawan selama delapan jam sehari untuk lima hari kerja seminggu. Kinerja karyawan ditentukan oleh tingkat kehadiran karyawan dalam mengerjakannya.

\section{Kemampuan kerja sama}

Tidak semua pekerjaan dapat diselesaikan oleh satu orang karyawan saja. Untuk jenis pekerjaan tertentu mungkin harus diselesaikan oleh dua orang karyawan atau lebih, sehingga membutuhkan kerja sama antar karyawan sangat dibutuhkan.

\section{METODOLOGI}

1. Jenis Penelitian

Penelitian kuantitatif adalah suatu penelitian yang menekankan analisisnya pada data-data numerikal (angka) yang selanjutnya diolah dengan metode statistika (Fauzi, 2009). Penulis menggunakan data dari formulir penilaian kinerja mahasiswa yang diisi oleh pihak Hotel sebagai bentuk tolak ukur penilaian kinerja selama magang.

2. Teknik Pengumpulan Data

Teknik pengumpulan data dalam penelitian ini berasal dari dua sumber yaitu data primer dan juga data sekunder. Untuk sumber data penelitian ini berupa pendapat pengguna Mahasiswa Akademi XYZ yang diperoleh dari form training evaluation sebagai alat kuesioner dengan menggunakan pertanyaan sesuai teori yang dikembangkan, observasi langsung ke lapangan saat monitoring mahasiswa di periode on the job training dan wawancara dengan pihak HRD.

Data sekunder eksternal yang digunakan merupakan data informasi yang didapat dari buku-buku, jurnal terdahulu yang dapat mendukung serta dapat digunakan sebagai pedoman dalam penelitian ini. Untuk itu dalam penelitian ini memerlukan teori yang berkaitan dengan Kinerja Karyawan serta On the Job Training Program.

\section{Populasi dan Sampel}

Adapun populasi dari penelitian ini adalah seluruh mahasiswa Akademi XYZ yang sedang melaksanakan periode On the Job Training di Hotel Bintang 5 sebanyak 36 orang. Menurut Sugiyono (2015) sampling jenuh adalah teknik penentuan sampel bila semua anggota populasi yang digunakan sebagai sampel. Hal ini sering dilakukan bila jumlah populasi relatif kecil, atau penelitian yang ingin membuat generalisasi dengan kesalahan yang sangat kecil. Berdasarkan teori-teori di atas, penulis menggunakan teknik sampling jenuh karena jumlah populasi mahasiswa yang melaksanakan OJT hanya terdapat 36 
orang, maka keseluruhan populasi dijadikan sampel.

\section{Teknik Analisis Data}

Dalam menganalisis data penelitian ini, penulis menggunakan form training evaluationyang diberikan langsung kepada pengguna mahasiswa yaitu Hotel bintang 5 yang tersebar di beberapa daerah. Dimana dalam form penilaian tersebut terbagi menjadi 4 penilaian yaitu:

- Skala 8-10 : Very Good (Sangat Bagus)

- Skala 6-8 : Good (Bagus)
- Skala 4-6 :Satisfactory (Cukup)

- Skala 0-4 : Need Improvement (Perlu Peningkatan)

Dimana total keseluruhan ada 10 aspek sehingga nantinya didapat nilai 100 sebagai nilai maksimal. Adapun dalam pembelajaran kategori yang digunakan dalam penilaian akademis adalah sebagai berikut:

Tabel 1. Tabel Penilaian Akademik

\begin{tabular}{|l|l|}
\hline $80,00-100,00$ & $=\mathrm{A}$ \\
\hline $73,00-79,99$ & $=\mathrm{B}+$ \\
\hline $66,00-72,99$ & $=\mathrm{B}$ \\
\hline $58,00-65,99$ & $=\mathrm{C}+$ \\
\hline $51,00-57,99$ & $=\mathrm{C}$ \\
\hline $41,00-50,99$ & $=\mathrm{D}$ \\
\hline $0,00-40,99$ & $=\mathrm{E}$ \\
\hline \multicolumn{2}{|c|}{ Sumber: Akademi XYZ (2016) }
\end{tabular}

\section{RESULT AND DISCUSSION}

Evaluasi yang dilakukan dalam penanganan Praktik Kerja Nyata atau biasa disebut program On The Job Training (OJT) melalui peninjauan nilai yang dimiliki oleh mahasiswa sepulang mereka menyelesaikan program OJT. Nilai tersebut diberikan oleh atasan dari tempat mahasiswa melakukan OJT di hotel bintang 4 atau bintang 5. Serta diverifikasi secara langsung oleh pihak Human Resources di Hotel tersebut sehingga tidak ada penilaian dengan subjektivitas. Penilaian tersebut memiliki kriteria yang diadaptasi dari teori kinerja karyawan juga implementasi di lapangan. Sehingga kesesuaian kriteria penilaian dapat terpenuhi untuk meninjau kinerja para mahasiswa selaku hotelier.Berikut evaluasi yang telah dimiliki oleh mahasiswa semester 3 dan semester 5 Program Studi Diploma III Perhotelan Akademi XYZ, yang berjumlah 36 orang, terdiri dari 11 orang mahasiswa semester 3 dan 25 orang mahasiswa semester 5 tersebar di 14 Hotel Bintang 5 di Jakarta, Semarang dan Bali.

Nilai yang diberikan oleh pihak hotel dengan menggunakan 5 (lima) dimensi pengukuran kinerja dari Bangun (2012), digunakanlah 10 pernyataan yang dapat mencerminkan efektifitas kinerja dari para mahasiswa di mata para penggunanya saat mereka on the job training. Dari 10 kategori yang dinilai, didapat nilai tertinggi untuk kategori Kesediaan untuk bekerjasama dan melaksanakan permintaan sebesar 8,95 dan juga nilai terendah untuk kategori Berpikir yang membangun dan mempunyai inisiatif untuk bertindak sebesar 8,21. Hasil ini memperlihatkan bahwa dalam melakukan pekerjaan untuk bekerja sama dalam sebuah tim di hotel, mahasiswa sudah dapat beradaptasi dengan baik. Tentunya hal ini merupakan hal positif yang terus dapat dipertahankan agar mahasiswa nantinya lebih mudah dalam bekerja sama antar kolega di industri selepas jenjang 
akademik mereka. Tetapi harap diperhatikan bahwa dalam bekerja, tingkat inisiatif sangat diperlukan untuk berkembangnya seorang individu dalam pekerjaannya. Sehingga pihak institusi dapat memperhatikan mata kuliah apa saja yang meningkatkan inisiatif para mahasiswa dalam mengambil keputusan dalam bekerja. Terlebih bila mereka nantinya telah mendapatkan posisi dengan jabatan di level supervisor keatas mereka akan tertantang dalam memutuskan suatu tindakan dengan sebab akibat yang begitu beragam.

\section{Tabel 2. Penilaian Mahasiswa Magang Akademi XYZ Berdasarkan Kategori}

\begin{tabular}{|l|r|}
\hline \multicolumn{2}{|c}{ Kinerja } \\
\hline Kategori Kinerja & Penilaian \\
\hline Memahami semua tingkat pekerjaan & 8,32 \\
\hline $\begin{array}{l}\text { Kemampuan untuk belajar dan } \\
\text { memenuhi keadaan yang berubah }\end{array}$ & 8,70 \\
\hline Penampilan, seragam lengkap, senyum & 8,79 \\
\hline $\begin{array}{l}\text { Berpikir yang membangun dan } \\
\text { mempunyai inisiatif untuk bertindak }\end{array}$ & 8,21 \\
\hline Hasil pekerjaan yang memuaskan & 8,36 \\
\hline $\begin{array}{l}\text { Memenuhi standar dan harapan } \\
\text { pelanggan }\end{array}$ & 8,35 \\
\hline $\begin{array}{l}\text { Sesuai dengan peraturan perusahaan dan } \\
\text { pedoman pelatihan }\end{array}$ & 8,64 \\
\hline $\begin{array}{l}\text { Jumlah absen yang berlebihan, terlambat } \\
\text { atau sakit }\end{array}$ & 8,70 \\
\hline $\begin{array}{l}\text { Sopan Santun, bekerja sama dengan tamu } \\
\text { dan karyawan lainnya }\end{array}$ & 8,76 \\
\hline $\begin{array}{l}\text { Kesediaan untuk bekerjasama dan } \\
\text { melaksanakan permintaan }\end{array}$ & 85,78 \\
\hline Total Penilaian & 8,95 \\
\hline \multicolumn{1}{|l|}{ Sumber: Olahan Penuls } \\
\hline
\end{tabular}

Sumber: Olahan Penulis (2019)

Berdasarkan nilai masing-masing kategori maka didapat nilai keseluruhan sebesar 85,78 yang masuk dalam kategori penilaian akademik A. Penilaian ini memperlihatkan standar kualitas kinerja mahasiswa Akademi XYZ dalam melakukan OJT di Hotel bintang 5 memiliki nilai rerata A dalam range 80,00 - 100. Adapun untuk mahasiswa yang memiliki nilai diatas nilai rerata keseluruhan sebanyak 17 orang mahasiswa yang terdiri dari 3 orang mahasiwa semester 3 dan 14 orang mahasiswa semester 5. Nilai tertinggi yang diraih oleh mahasiswa Akademi XYZ adalah 100 dan yang paling rendah diangka 62. Dari penilaian tersebut dapat dilihat bahwa mahasiswa yang lebih berpengalaman di semester sebelumnya mendapat nilai yang lebih tinggi dibanding mahasiswa yang baru melakukan OJT untuk pertama kalinya. Dimana beberapa kategori penilaian diatas berkembang seiring bertambahnya pengetahuan dan kemampuan para mahasiswa baik dari OJT sebelumnya maupun dari kegiatan pembelajaran di Institusi. Hal tersebut didukung oleh beberapa pernyataan 
mahasiswa yang merasa mereka lebih siap dalam melakukan kegiatan OJT di semester 5 (lima) dibanding saat mereka semester 3(tiga) dikarenakan mereka sudah lebih mengetahui tujuan dari kegiatan tersebut dan kebutuhan yang diminta dari para pengguna, yakni Hotel Bintang 5.

Tabel 3. Hasil Evaluasi Kinerja Mahasiswa Magang di Hotel Bintang 5 dari Akademi XYZ

\begin{tabular}{|l|r|r|}
\hline Skala & $\begin{array}{l}\text { Jumlah } \\
\text { Mahasiswa }\end{array}$ & Persentase \\
\hline $80,00-100,00$ & 29 & $80,56 \%$ \\
\hline $73,00-79,99$ & 5 & $13,89 \%$ \\
\hline $66,00-72,99$ & 1 & $2,78 \%$ \\
\hline $58,00-65,99$ & 1 & $2,78 \%$ \\
\hline $51,00-57,99$ & 0 & $0,00 \%$ \\
\hline $41,00-50,99$ & 0 & $0,00 \%$ \\
\hline $0,00-40,99$ & 0 & $0,00 \%$ \\
\hline
\end{tabular}

Sumber: Olahan Penulis (2019)

Tentunya dengan hasil evaluasi kinerja seperti ini, pihak Akademi XYZ harus mempertahankan program pembelajaran yang telah dimiliki dan tidak melupakan nilai-nilai yang ada dalam masing-masing kategori. Dimana keseluruhan dimensi tersebut diberikan kepada mahasiswa saat perkuliahan di semester 1,2, 4 dan 6. Dimulai dari penerapan etika dalam perkuliahan dan bekerja, hingga pemahaman mengenai job description serta inisiatif mahasiswa hendaknya dibangun sejak awal perkuliahan agar menjadi bekal seluruh mahasiswa saat lulus nanti.

\section{SIMPULAN}

Penilaian kinerja mahasiswa saat melakukan kegiatan On The Job Training (OJT) merupakan salah satu cara yang dapat dilakukan oleh sebuah Institusi Akademik dalam mengevaluasi hasil capaian dari pembelajaran yang telah diberikan saat perkuliahan. Hal ini yang diterapkan oleh Akademi XYZ dimana sistem pembelajarannya sendiri terdiri dari
70\% Praktik dan 30\% Teori. Sehingga kegiatan OJT merupakan sebuah pembuktian dari seluruh kegiatan praktik yang telah dilaksanakan di Akademi apakah mahasiswa mampu menyerap dan menggunakan ilmu yang telah diberikan di industri, khususnya di Hotel Bintang 5 sebagai industri teratas di dalam dunia Perhotelan.

Berdasarkan data yang didapat dari penilaian masing-masing pengguna mahasiswa di industri menggunakan sistem penilaian yang sesuai dengan Akademi, 36 mahasiswa Akademi XYZ yang melakukan OJT di Hotel Bintang 5 memiliki nilai rata-rata 85,78 yang secara akademis masuk ke dalam kategori penilaian A (Sangat baik). Dengan kategori tertinggi adalah kemampuan kerjasama sebesar 8,86 dan kategori terendah adalah kualitas pekerjaan sebesar 8,43 . Diharapkan dengan nilai yang telah dimiliki Akademi XYZ mampu mempertahankan kualitas dari mahasiswa di industri serta meningkatkan kategori yang masih kurang. 
Berdasarkan hasil penelitian dan simpulan yang ada, lulusan Akademi XYZ kedepannya dapat beradaptasi dengan dunia kerja, khususnya di hotel bintang 5 , tetapi dengan nilai yang belum maksimal di beberapa kategori dapat berimplikasi dalam berkembangnya mereka di dunia kerja. Secara individu, karir mereka akan terhenti bila pihak Institusi tidak meningkatkan pembelajaran yang menunjang kategori kualitas pekerjaan, khususnya untuk kategori Berpikir yang membangun dan mempunyai inisiatif untuk bertindak.

\section{DAFTAR PUSTAKA}

\section{Artikel Dalam Jurnal}

Hughes,

Karen, Mylonas,

Aliisa and Benckendorff,

Pierre (2013). Students' reflections on industry placement: comparing four undergraduate work integrated learning streams.Asia-Pacific Journal of Cooperative Education. Volume 14, No.4, 265-279.

Joslam, B. M., Crustinger, C., Reynolds, J. S., Dotter, T., Thozhur, S., Baum, T., and Devine, F. G. (2009). An empirical study of the work attitudes of Generation Y college students in the USA: The case of hospitality and merchandising undergraduate majors. Journal of Service Research, Volume 9, 5-30.

Pool, Lorraine Dacre and Sewell, Peter. 2007. The key to employability: developing a practical model of graduate employability Education $\mathrm{p}$ Training Vol. 49 No. 4, 277-289

Solnet, D., Robinson, R.N.S., and Cooper, C. 2007. An industry partnerships approach to tourism education. Journal of Hospitality, Leisure, Sport \& Tourism Education, Volume 6, No. 1, 66-70.

Wang, H., Kong, M., Shan, W., and Vong, S. K. (2010). The effects of doing part-time jobs on college student academic performance and social life in a Chinese society. Journal of Education and Work, Volume 23, 79-94.

\section{Buku Teks}

Arikunto, S. (2009). Prosedur Penelitian: Suatu Pendekatan Praktik,Jakarta, Rineka Cipta.

Aritonang, R. Lerbin, R. (2007). Teori dan Praktik Riset Pemasaran, Bogor, Ghalia Indonesia.

Baker, L, Caldicott, J \& Spowart, J . (2011), Cooperative and workintegrated education in integrated education (2nd edition), New Zealand,World Association for Cooperative Education

Bangun, W. (2012). Manajemen Sumber Daya Manusia, Jakarta, Erlangga.

Budihardjo. (2016). Panduan Praktis Menyusun SOP, Jakarta, Penebar Swadaya

Cha, Sumarsono. (2016). Dahsyatnya Bisnis Hotel di Indonesia, Jakarta, PT Gramedia Pustaka Utama.

Fauzi. (2009). Metode Kuantitatif, Jakarta, Erlangga.

Hair, Joseph F., et.al. (2009). Marketing Research: In Digital Information Environment (4th Edition), New York, The McGraw-Hill Companies, Inc,. (2010). Multivariate Data Analysis (7th Edition), New York, Prentice Hall International, Inc.

Hamali, Arif Yusuf. (2016). Pemahaman Manajemen Sumber Daya Manusia. Yogyakarta: CAPS (Center for Academic Publishing Service).

Handoko, T. Hani. (2010). Manajemen Personalia \& Sumber daya Manusia, Yogyakarta, BPFE.

Hariandja, Marihot Tua Efendi. (2007). Manajemen Sumber Daya Manusia (Pengadaan, Pengembangan, Pengkompensasian, dan 
Peningkatan Produktivitas Pegawai), Jakarta, Grasindo.

Hasibuan, H. Malayu. (2014). Manajemen Sumber Daya Manusia (Edisi Revisi). Jakarta: Bumi Aksara.

Komar, Richard. (2016). Hotel Management, Jakarta, PT. Grasindo.

Kriyantono, Rachmat. (2012). Teknik praktis Riset Komunikasi, Jakarta, Kencana.

Mangkunegara, A.A Anwar Prabu. (2010). Evaluasi Kinerja SDM, Bandung, PT Revika Aditama.

Marwansyah. (2010). Manajemen Sumber Daya Manusia (Edisi Ke-2), Bandung, Alfabeta.

Narimawati, Umi. (2008). Metodologi Penelitian Kualitatif dan Kuantitatif: Teori dan Aplikasi, Bandung, Agung Media.

Prawirosentono, S. (2008). Manajemen Sumber Daya Manusia, Yogyakarta, BPFE.

Priyatno, Dwi. (2009). Mandiri Belajar Spss, Cetakan kedua, Jakarta, PT. Buku Kita.

Robbin, P.S \& Judge, T.A. (2008). Perilaku Organisasi, (Edisi Ke-12), Jakarta, Salemba Empat. . (2011). Perilaku Organisasi, Buku 2 (Edisi ke-12), Jakarta, Salemba Empat.

Sekaran, Uma dan Bougie, Roger. (2013). Research Methods for Bussiness: A skill Building Approach (6th Edition),New Dehli, Wiley.

Simamora, Henry. (2008). Manajemen Sumber daya Manusia, Yogyakarta, STIE YKPN Yogyakarta.

Siregar, Syofian. (2014). Metode Penelitian Kuantitatif, Jakarta, Kencana.

Sugiyono. (2015). Metode Penelitian Manajemen, Bandung, Alfabeta.

Sulastiyono, Agus. (2011). Manajemen Penyelenggaran Hotel, Bandung, Alfabeta.
Sule, Tinawati dan Saefullah, Kurniawan. (2015). Pengantar Manajemen (Edisi Ke-1), Jakarta, Prenadamedia Group.

Sunyoto, D. (2012). Manajemen Sumber Daya Manusia, Yogyakarta, CAPS (Center for Academic Publising Service).

Supriyanto. (2009). Metodologi Riset Bisnis, Jakarta, Index.

Sutrisno, Edy. (2009). Manajemen Sumber Daya Manusia (Edisi Ke-1), Jakarta, Kencana Prenada Media Group. . (2011). Manajemen Sumber Daya Manusia, Jakarta, Kecana Prenada Media Group.

Suwatno. (2011). Manajemen Sumber Daya Manusia Dalam Organisasi Publik dan Bisnis, Bandung, Alfabeta.

Swasto, Bambang. (2011). Manajemen Sumber Daya Manusia, Malang, Universitas Brawijaya Press (UB Press).

Tehubijuluw, Florentina K. dan Sugiarto. (2014).

Metodologi

Penelitian,Tangerang, Matana Bina Utama.

Uno, Hamzah B. (2009). Teori Motivasi dan Pengukurannya (Analisis di bidang pendidikan), Jakarta, Bumi Aksara.

Wibowo. (2014). Manajemen Kinerja (Edisi Ke-4),Jakarta, Raja Grafindo Persada.

Wirawan. (2009). Evaluasi Kinerja Sumber Daya Manusia, Jakarta, Salemba Empat

\section{Website}

Badan Pusat Statistik. (2017). Angka Beban Tanggungan [Online] Tersedia di https://www.bps.go.id/index.php/is tilah/index? Istilah_page $=4$

Berita Resmi Statistik Provinsi DKI Jakarta. (2016, Februari 01). Pariwisata DKI Jakarta. Diunduh 
(p- ISSN 1858-0112, e-ISSN 15537-37677) http://jurnal.unmuhjember.ac.id/index.php/wisata

23 Februari 2017), dari https://jakarta.bps.go.id/backend/br s_ind/brsInd-20160202100311.pdf

Hukum Online.Com. (2003). UU Ketenagakerjaan Baru [Online] Tersedia di http://www.hukumonline.com/berit a/baca/hol7529/uu-

ketenagakerjaan-baru

Poerwanto, Endy. (2016). BPS: Tingkat Hunian Berbintang Naik [Online] Tersedia di http://bisniswisata.co.id/bpstingkat-hunian-hotel-berbintang$\underline{\text { naik/ }}$ 